\title{
Aplasia pura de células rojas secundaria a infección por parvovirus B19 en paciente VIH positivo
}

\author{
Pure red cell aplasia secondary to \\ parvovirus B19 infection in an HIV positive \\ patient
}

\author{
Larry Luber Martínez, Mariana Montoya, \\ Juan David Berlinghieri • Medellín (Colombia)
}

\section{Resumen}

La infección crónica por parvovirus B19 en pacientes seropositivos para el virus de inmunodeficiencia humana (VIH) es una causa identificable y tratable de anemia en esta población, que en nuestro medio aún no ha sido muy estudiada. La búsqueda activa de este patógeno en pacientes VIH positivos con anemia grave sin compromiso de otras líneas celulares puede llevar a una mejoría en la calidad de vida en el tiempo y reducción de los costos de la enfermedad para el sistema de salud. Nosotros presentamos el caso de un paciente con síndrome de inmunodeficiencia adquirida y anemia a quien se le identifico parvovirus B19. (Acta Med Colomb 2018; 43: 42-44).

Palabras clave: parvovirus humano B19, VIH-1, anemia, aplasia pura de glóbulos rojos, calidad de vida

\begin{abstract}
The chronic infection by parvovirus B19 in seropositive patients for the human immunodeficiency virus (HIV) is an identifiable and treatable cause of anemia in this population, which in our environment has not yet been widely studied. The active search for this pathogen in HIV positive patients with severe anemia without compromising other cell lines can lead to an improvement in the quality of life over time and reduction of the costs of the disease to the health system. We present the case of a patient with acquired immunodeficiency syndrome and anemia who was identified as parvovirus B19. (Acta Med Colomb 2018; 43: 42-44).
\end{abstract}

Key words: Human parvovirus B19, HIV-1, anemia, pure red cell aplasia, quality of life.
Doctor Larry Luber Martínez Rosado: Internista, Infectólogo Hospital La María; Dra. Mariana Montoya Castillo: Médica General Universidad CES; Dr. Juan David Berlinghieri Pérez: Médico General Universidad CES. Medellín (Colombia).

Correspondencia: Dra. Mariana Montoya Castillo. Medellín (Colombia).

E-mail: marimontoya13@gmail.com

Recibido: 25/III/2017 Aceptado: 25/I/2018

\section{Introducción}

El parvovirus B19 es un virus DNA monocatenario desnudo cuya cápside mide aproximadamente $25 \mathrm{~nm}$, tiene tropismo por los precursores eritroides en la médula ósea, generando apoptosis de éstos, lo que en pacientes inmunocomprometidos conlleva a aplasia de la serie eritroide produciendo así anemia crónica grave (1), recibimos en nuestro servicio a un paciente conocido por tener infección por VIH de varios años de evolución, sin tratamiento antirretroviral, al ingreso, entre otros hallazgos, se le documentó anemia que requería de la administración periódica de hemoderivados, posteriormente se encontró que la causa de la anemia era una coinfección crónica con parvovirus B19, a continuación describimos el caso de este paciente.

\section{Presentación de caso}

Masculino de 35 años de edad con antecedente desde el año 2008 de infección por virus de la inmunodeficiencia humana, se le inició terapia antirretroviral, la cual abandonó de forma definitiva tres meses después de hacérsele el diagnóstico. Ingresó al servicio de urgencias de nuestra institución refiriendo dolor sobre uno de sus costados en relación a lesiones de herpes zóster, traía consigo un conteo de linfocitos CD4 en 19 células/microlitro de un mes atrás. A la exploración física se le encontraba en malas condiciones generales, emaciado con palidez mucocutánea generalizada, adenopatías cervicales de consistencia pétrea, lesiones costrosas dorsales y edema de miembros inferiores. Los paraclínicos de ingreso mostraron anemia microcítica 
hipocrómica y elevación de la proteína C reactiva, las ayudas diagnosticas tomadas posteriormente mostraron presencia de Mycobacterium tuberculosis en muestra de ganglio cervical, extendido de sangre periférica con un índice de reticulocitos de 0.3 , se solicitó serología IgM e IgG para parvovirus B19 que en ambos casos su resultado fue positivo (Tabla 1). Se le inicia esquema antituberculoso tetra conjugado y ulteriormente terapia antirretroviral con lo que se consigue mejoría de la aplasia pura de la serie roja y conjuntamente del estado general del paciente.

\section{Discusión}

La infección crónica por parvovirus B19 en pacientes con síndrome de inmunodeficiencia adquirida (SIDA), es una causa poco explorada de anemia en nuestro medio, en pacientes coinfectados con el virus de la inmunodeficiencia humana (VIH); la presencia de este virus en muestras de origen humano fue descrita por primera vez en 1975 en Londres, Reino Unido, por la viróloga Yvonne Cossart quien lo descubrió de forma incidental en muestras de donantes de sangre sanos (2); su relación con el VIH se estudió hacia finales de la década de 1980, encontrándose como causa tratable de anemia en pacientes coinfectados con el virus anteriormente mencionado (3) .

El parvovirus B19 pertenece a la familia Parvoviridae y a la subfamilia Parvovirinae género Erythroparvovirus; es un virus desnudo cuyo genoma consiste en una cadena de ADN lineal de cadena simple, de 5596 nucleótidos de longitud; las proteínas más importantes codificadas en el genoma viral son: la NS1 que acompaña al genoma del virus durante su replicación y regula la expresión génica viral, las otras dos proteínas son la VP1 y la VP2 que conforman la cápside de forma icosaédrica, la cual está compuesta por sesenta proteínas (tres por cara) siendo 96\% VP1 y 4\% VP2; ambas tienen la capacidad de fijarse al receptor de superficie en la célula diana conocido como antígeno $P$.

Luego de fijarse al antígeno P, VP1 interactúa con un correceptor que permite la internalización del virus y su tránsito hasta el núcleo celular donde el genoma viral es replicado y se ensamblan los viriones que posteriormente abandonan la célula infectada. Un punto cardinal en la fisiopatología de la enfermedad radica en el proceso de síntesis de las proteínas virales, puntualmente la NS1; ésta paraliza la célula en la fase G2 del ciclo celular y posteriormente induce la muerte celular por apoptosis, lo que explica la naturaleza aplásica de la anemia producida por parvovirus B19 $(4,5)$.

En la línea eritropoyética la infección se da a nivel de las células progenitoras conocidas como unidades formadoras eritrocíticas explosivas (BFU-E) y las unidades formadoras de colonias eritrocíticas (CFU-E); estas células son las primeras en el linaje que termina en el eritrocito maduro (6). Lo anterior se relaciona directamente con que la alteración hematológica típica presentada en el contexto de la infección por el parvovirus B19, sea una afectación individual de la eritropoyesis denominada como aplasia
Tabla 1. Paraclínicos.

\begin{tabular}{|c|c|}
\hline Paraclínico & Resultado \\
\hline Hemoglobina & $6.2 \mathrm{~g} / \mathrm{dL}$ \\
\hline Hematocrito & $20.4 \%$ \\
\hline Volumen corpuscular medio & $81 \mathrm{fL}$ \\
\hline Hemoglobina corpuscular media & $25.4 \mathrm{pg}$ \\
\hline Leucocitos & $5070 \mathrm{cel} / \mathrm{uL}$ \\
\hline Plaquetas & 392000 \\
\hline Recuento de linfocitos T CD4+ & $19 \mathrm{cel} / \mathrm{uL}$ \\
\hline Proteína $\mathrm{C}$ reactiva & $18.49 \mathrm{mg} / \mathrm{dL}$ \\
\hline Índice de reticulocitos & 0.3 \\
\hline Epstein-Barr virus IgM & 0.85 negativo \\
\hline $\begin{array}{l}\text { Criptococcus aglutinación de antíge- } \\
\text { no en látex (en sangre) }\end{array}$ & Negativo \\
\hline Histoplasma antígeno en orina & Negativo \\
\hline $\begin{array}{l}\text { M.tuberculosis identificación por } \\
\text { PCR (ganglio cervical) }\end{array}$ & Positivo \\
\hline $\begin{array}{l}\text { Tomografía computada - alta reso- } \\
\text { lución (tórax) }\end{array}$ & $\begin{array}{l}\text { Hallazgos en el parén- } \\
\text { quima pulmonar com- } \\
\text { patible con infección } \\
\text { pulmonar. Adenopatías } \\
\text { mediastínicas e hilia- } \\
\text { res bilaterales, engro- } \\
\text { samiento pleural en el } \\
\text { lóbulo medio. }\end{array}$ \\
\hline Parvovirus B19 IgM & 16.6 (positivo) \\
\hline Parvovirus B19 IgG & 3.5 (negativo) \\
\hline
\end{tabular}

pura de células rojas, en personas inmunocompetentes que padecen de algún desorden que afecta la integridad de los eritrocitos (p. ej. anemia de células falciformes); la forma hematológica de la infección aguda se manifiesta como una crisis aplásica transitoria (CAT), la cual se caracteriza por una anemia grave que suele mejorar cuando se genera inmunidad protectora alrededor de los 20 días luego del inicio de la infección (1). En individuos inmunodeficientes coinfectados con el VIH, la infección por el parvovirus B19 tiende a cronificarse llevando a anemia grave, debido a que no se crean anticuerpos neutralizantes contra el virus, de forma contraria a lo que ocurre en los pacientes que padecen crisis aplásica transitoria (7).

La transmisión del virus de persona a persona se da por el contacto con secreciones respiratorias de una persona infectada, y también, el contacto con fómites es una vía de adquisición relevante para el parvovirus B19 debido a que éste al ser un virus desnudo muestra una alta supervivencia en el ambiente. En los países con estaciones, las infecciones se dan más frecuentemente al final del invierno y a principios de la primavera, con picos cada tres a cuatro años (8). En 
nuestro medio aún no se cuenta con estudios que muestren la prevalencia del virus en población VIH positiva por detección de inmunoglobulinas específicas o ADN viral, sin embargo, se cuenta con datos de un estudio realizado en Brasil, cuya población es comparable con la nuestra; allí se encontró que la prevalencia de anticuerpos IgG era del $62.9 \%$, el recuento de CD4 promedio era de 311 células/uL y el porcentaje de pacientes con recuento de CD4 inferior a 100 células/uL era de $21 \%$ (9). En Colombia hacen falta estudios que permitan conocer la prevalencia del virus en la población VIH positiva y su relación con el estado virológico e inmunológico de la misma.

El diagnóstico de la infección por parvovirus B19, en población VIH positiva se hace sumando la historia de anemia en el paciente con los hallazgos en el cuadro hemático compatible con esta enfermedad; por tratarse de una anemia causada por destrucción de las células precursoras de los eritrocitos en la médula ósea, se encontrara que el índice de reticulocitos va a estar marcadamente disminuido (3); para confirmar el diagnóstico se solicitan las inmunoglobulinas específicas y amplificación del ADN viral. El último método se prefiere en pacientes con infección crónica debido a que pueden presentar una producción deficiente de anticuerpos contra el virus (1). El tratamiento de la infección por el parvovirus y la anemia relacionada a éste, se basa en dos terapias fundamentales: el uso de un esquema antirretroviral y el uso de inmunoglobulina intravenosa; el primero se basa en la recuperación del estado inmunológico lo cual conlleva al establecimiento de una respuesta inmune efectiva para neutralizar el virus (10). Un efecto secundario importante asociado a la instauración de terapia antirretroviral en pacientes con SIDA, es el desarrollo del síndrome de reconstitución inmune, el cual se ha descrito en pocos casos reportados en la literatura como un deterioro en el estado hematológico del paciente luego de iniciada la terapia antiretroviral y haberse controlado la aplasia de la serie roja (11). También se encuentran reportados casos de encefalitis como presentación del síndrome de reconstitución inmune en pacientes con infección por parvovirus B19 (12). El uso de inmunoglobulina intravenosa se fundamenta en dotar al paciente de una fuente externa de anticuerpos para que se logre la neutralización del virus; esta terapia se ha descrito desde que se hicieron las primeras asociaciones entre el parvovirus B19 y el VIH. Debido a que se puede lograr control de la enfermedad por el parvovirus con la terapia antirretroviral que debe consumir el paciente con VIH, se prefiere usar la inmunoglobulina intravenosa en aquellos individuos que tienen anemia grave o presentan aplasia persistente, aún con el uso de medicamentos antirretrovirales (13).

La importancia de este caso yace en que la infección por parvovirus B19 en pacientes coinfectados con el VIH es una causa de gran morbilidad y deterioro en la calidad de vida de esta población, debido a la gravedad y la cronicidad de la anemia que produce, adicionalmente el requerimiento periódico de internamientos y utilización de hemoderivados incrementa el costo del tratamiento al largo plazo. Actualmente esta entidad no es ampliamente reconocida en nuestro medio y se requieren estudios para caracterizar nuestra población.

\section{Referencias}

1. Young NS, Brown KE. Parvovirus B19. N Engl J Med [Internet]. 2004 Feb 5;350(6):586-97. Available from: http://www.nejm.org/doi/abs/10.1056/NEJM$\mathrm{ra} 030840$

2. Cossart YE, Field AM, Cant B, Widdows D. Parvovirus-like particles in human sera. Lancet. 1975;1(7898):72-3.

3. Frickhofen N,Abkowitz JL, Safford M BM. Persistent B19 parvovirus infection in patients infected with human immunodeficency virus type 1 (HIV-1): a treatable cause of anemia in AIDS. Ann Intern Med [Internet]. 1990;113(12):926-33. Available from: http://web.b.ebscohost.com.bdigital.ces.edu.co:2048/ehost/detail/ detail?sid=7f9e743f-3e 25-48d0-9f44-f87d82888bf6\%40sessionmgr103\&vid=0 \& hid=128\&bdata=Jmxhbmc9ZXMmc210ZT1laG9zdC1saXZlJnNjb3BIPXNpdGU $\% 3 \mathrm{~d} \# \mathrm{db}=\mathrm{mdc} \& \mathrm{AN}=2173460$

4. Qiu J, Söderlund-Venermo M, Young NS. Human Parvoviruses. Clin Microbiol Rev [Internet]. 2017 Jan 2; 30(1): 43-113. Available from: http://cmr.asm.org/ lookup/doi/10.1128/CMR.00040-16

5. Kerr J. A review of blood diseases and cytopenias associated with human parvovirus B19 infection. Rev Med Virol. 2009; 19(1): 57-64.

6. Mortimer P, Young N. A human paraovirus-like virus inhibits haematopoietic colony formation in vitro. Nature. 1983; 302(31): 426-9.

7. Kurtzman G, Frickhofen N KJ. Pure red-cell aplasia of 10 years duration due to persistent parvovirus B19 infection and its cure with immunoglobulin therapy. N Engl J Med. 1989; 321(8): 519-23.

8. Servant-Delmas A, Morinet F. Update of the human parvovirus B19 biology. Transfus Clin Biol [Internet]. Elsevier Masson SAS; 2016; 23(1): 5-12. Available from: http://dx.doi.org/10.1016/j.tracli.2015.11.006

9. Azevedo KML De, Setúbal S, Camacho LAB, Velarde LGC, Oliveira SA De. Seroepidemiological study of human parvovirus B19 among human immunodeficiency virus-infected patients in a medium-sized city in Rio de Janeiro, Brazil. Mem Inst Oswaldo Cruz. 2009; 104(6): 901-4.

10. Mylonakis E, Dickinson BP, Mileno MD, Flanigan T, Schiffman FJ, Mega A, et al. Persistent parvovirus B19 related anemia of seven years' duration in an HIVinfected patient: Complete remission associated with highly active antiretroviral therapy. Am J Hematol. 1999; 60(2): 164-6.

11. Watanabe D, Taniguchi T, Otani N, Tominari S, Nishida Y, Uehira T, et al. Immune reconstitution to parvovirus B19 and resolution of anemia in a patient treated with highly active antiretroviral therapy. I Infect Chemother Off J Japan Soc Chemother. 2011;17(2):283-7.

12. Fabiola CD, Angel MM. Encefalitis por Parvovirus B19 una manifestación poco común de Síndrome Inflamatorio de Reconstitución Inmunológica en SIDA Encephalitis by parvovirus B19: An uncommon manifestation of immune reconstitution syndrome on AIDS. Rev médica MD. 2011; 3(2): 124-7.

13. Mouthon L, Guillevin L, Tellier Z. Intravenous immunoglobulins in autoimmune- or parvovirus B19-mediated pure red-cell aplasia. Autoimmun Rev. 2005; 4(5): 264-9. 